\title{
Bioelectrical Impedance Analysis Derived-Phase Angle as a Pragmatic Tool to Detect Protein Energy Wasting among Multi-Ethnic Hemodialysis Patients
}

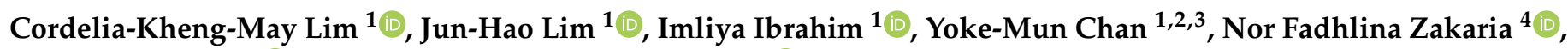 \\ Rosnawati Yahya ${ }^{5}$ and Zulfitri Azuan Mat Daud ${ }^{1,2,3, * \mathbb{D}}$ \\ 1 Department of Dietetics, Faculty of Medicine and Health Sciences, Universiti Putra Malaysia, \\ UPM Serdang 43400, Malaysia; cordeliamay07@gmail.com (C.-K.-M.L.); sinhao0624@yahoo.com (J.-H.L.); \\ imliya.ibrahim@gmail.com (I.I.); cym@upm.edu.my (Y.-M.C.) \\ 2 Research Center of Excellent (RCoE) Nutrition and Non-communicable Diseases, Faculty of Medicine and \\ Health Sciences, Universiti Putra Malaysia, UPM Serdang 43400, Malaysia \\ 3 Department of Dietetics, Hospital Pengajar Universiti Putra Malaysia, UPM Serdang 43400, Malaysia \\ 4 Department of Medicine, Faculty of Medicine and Health Sciences, Universiti Putra Malaysia, \\ UPM Serdang 43400, Malaysia; n_fadhlina@upm.edu.my \\ 5 Department of Nephrology, Hospital Kuala Lumpur, Kuala Lumpur 50586, Malaysia; rosnayahya@gmail.com \\ * Correspondence: zulfitri@upm.edu.my; Tel.: +603-9769-2431
}

check for updates

Citation: Lim, C.-K.-M.; Lim, J.-H.; Ibrahim, I.; Chan, Y.-M.; Zakaria, N.F.; Yahya, R.; Daud, Z.A.M. Bioelectrical Impedance Analysis Derived-Phase Angle as a Pragmatic Tool to Detect Protein Energy Wasting among Multi-Ethnic Hemodialysis Patients. Diagnostics 2021, 11, 1745. https:// doi.org/10.3390/diagnostics11101745

Academic Editor: Andreas Kjaer

Received: 20 July 2021

Accepted: 19 September 2021

Published: 23 September 2021

Publisher's Note: MDPI stays neutral with regard to jurisdictional claims in published maps and institutional affiliations.

Copyright: (c) 2021 by the authors. Licensee MDPI, Basel, Switzerland. This article is an open access article distributed under the terms and conditions of the Creative Commons Attribution (CC BY) license (https:// creativecommons.org/licenses/by/ $4.0 /)$.
Abstract: Protein-energy wasting (PEW) is a devastating metabolic derangement that leads to increased morbidity and mortality in hemodialysis (HD) patients. This study aimed to determine the diagnostic test accuracy of bioelectrical impedance analysis derived-phase angle (PhA) in detecting PEW among HD patients. This was a multi-centre, cross-sectional study conducted amongst 152 multiethnic HD patients in Klang Valley, Malaysia. PEW was assessed using the International Society of Renal Nutrition and Metabolism criteria as the reference method. PhA was measured using a multi-frequency bioelectrical impedance spectroscopy at $50 \mathrm{kHz}$. Multiple and logistic regressions were used to determine factors associated with PhA and PEW diagnosis, respectively. A receiver operating characteristics curve analysis was used to establish the gender-specific PhA cut-offs to detect PEW. PEW existed in $21.1 \%$ of the HD patients. PhA was found as an independent predictor of PEW (adjOR $=0.308, p=0.001$ ), with acceptable to excellent discriminative performance (adjAUC $_{\text {male }}=0.809 ;$ adjAUC female $\left.=0.719\right)$. Male patients had higher PhA cut-off compared to female patients $\left(4.26^{\circ}\right.$ vs. $\left.3.30^{\circ}\right)$. We concluded that $\mathrm{PhA}$ is a valid and pragmatic biomarker to detect PEW in multi-ethnic Malaysian HD patients and a gender-specific cut-off is necessary, attributed to the gender differences in body composition.

Keywords: phase angle; bioelectrical impedance; body composition; protein energy wasting; hemodialysis

\section{Introduction}

In the 21st century, the nutrition paradigm has been shifting towards combating protein energy wasting (PEW) in the HD population [1]. PEW is a maladaptive metabolic state in which both body protein mass and energy fuel reserves are depleted [2]. PEW is prevalent in patients with chronic kidney disease (CKD) and worsens over time as the disease progresses (from < 5\% in CKD Stage 1-2 up to 11-54\% in CKD Stage 3-5) [3-5]. A meta-analysis reported that the global prevalence of PEW among dialysis patients ranged from $28.0 \%$ to $54.0 \%$ [5]. The etiology of PEW is multifactorial, namely including decreased dietary intake, inflammation, metabolic derangements, comorbidities, and dialysis treatment [6]. The consequences of PEW include weakness, poor quality of life, increased risk of hospitalisation, and heightened morbidity and mortality $[7,8]$. The total annual cost for end-stage renal disease (ESRD) expenditure was reported to be approximately 100,000 USD 
per patient [9]. On top of that, there has been considerable cost required for the healthcare expenses of ESRD patients with PEW due to higher rates of hospitalisation and recurrent visits to the emergency department or outpatient clinics [10]. Hence, the presence of PEW in the ESRD population would further worsen the global economic burden.

Regular assessment is crucial to detect PEW in these vulnerable populations for better nutritional outcomes and survival. The International Society of Renal Nutrition and Metabolism (ISRNM) expert panel have proposed a set of criteria to diagnose PEW in CKD patients [2]. Nonetheless, the ISRNM criteria are subjected to several constraints that limit their application in the clinical setting [11]. For instance, it requires multi-dimensional parameters to diagnose PEW, such as (i) body mass, (ii) serum chemistry, (iii) muscle mass, and (iv) dietary intake. These assessments demand well-trained personnel (i.e., dietitians) and can be cumbersome for them to perform due to time constraints. This creates a great challenge, especially in low- and middle- income countries where a dietitian shortfall (20-45\%) puts these countries in hot water [9].

As such, a bioelectrical impedance analysis (BIA)-derived phase angle (PhA) has been emerging as a valid proxy of PEW by assessing the nutritional state at the cellular level [11-15]. PhA is derived from the arc tangent value of the ratio of reactance $\left(X_{c}\right)$ to resistance (R) [16]. Reactance denotes cell membrane integrity, in which healthy cells have a more intact cellular membrane [17]. On the other side of the coin, resistance is the opposition to electrical current, and is inversely proportional to the amount of lean muscle mass in the body $[17,18]$. Therefore, PhA is considered an indicator of cellular health [19]. A higher PhA value is more favourable as it denotes better cellular function and life expectancy $[20,21]$.

Mounting evidence has supported the use of $\mathrm{PhA}$ as a prognostic indicator for various clinical conditions (i.e., cancer, cirrhosis, surgery, and frailty) [19,22-24]. Although PhA has also been proposed as a rapid, inexpensive, and non-invasive method to detect PEW among dialysis patients in several countries (i.e., China, Japan, Mexico, and Spain) [11-15], the extrapolation of their findings is questionable due to the variation in body composition across ethnicities [25] as evidenced by the inconsistent cut-offs identified (ranging from $3.7^{\circ}$ to $4.64^{\circ}$ ) [11-15]. In addition, the absence of gender-specific cut-offs for PhA might diminish its diagnostic accuracy for PEW detection. Therefore, in this present study, we aimed to: (i) examine the diagnostic test accuracy of $\mathrm{PhA}$, and (ii) to establish optimal gender-specific PhA cut-offs to detect PEW among multi-ethnic Malaysian HD patients.

\section{Materials and Methods}

\subsection{Study Design and Patient Recruitment}

A cross-sectional study was conducted among multi-ethnic HD patients residing in the Klang Valley, Malaysia. Subject recruitment commenced on February 2019 up to July 2019 at 9 conveniently selected HD centres, consisting of dialysis units in a tertiary government hospital, non-government organisations and private HD centres (within a $40 \mathrm{~km}$ radius from the Faculty of Medicine and Health Sciences, Universiti Putra Malaysia). Patients were eligible for participation if they were at least 18 years old and undergoing regular HD treatment 3 times per week for at least 6 months prior to the data collection. Patients were excluded if they had: (i) contraindications for BIA measurement (i.e., limb amputations, metallic implants, or having a pacemaker); (ii) visual, hearing or speech impairment; (iii) acquired immunodeficiency syndrome, malignancy, or underwent surgery that interfered with their nutritional status for the past 3 months; (iv) frailty or severely ill; (v) involved in a clinical trial; and (vi) cognitive impairment such as Alzheimer's or mental illness. This study was approved by the Ethics Committee of the National Medical Research Register, Ministry of Health, Malaysia (NMRR-18-1514-42126, approved on 18 September 2018)) and the Universiti Putra Malaysia Ethic Committee for Research Involving Human Subjects (JKEUPM-2019-064, approved on 1 February 2019). Both written and verbal informed consent were obtained from all the patients prior to their study participation. All research procedures were conducted in accordance with the World Medical Association- 
Declaration of Helsinki. The study sections were reported according to the Strengthening the Reporting of Observational Studies in Epidemiology (STROBE) checklist [26].

\subsection{Sample Size Requirement and Sampling Method}

Sample size was calculated using G. Power version 3.1.9.4 (Franz Faul, Universitat Kiel, Germany) statistical software for a Linear Multiple Regression: Fixed Model, $\mathrm{R}^{2}$ deviation from zero, with an effect size of 0.15 , statistical power of $80 \%, 5 \%$ level of significance, and with a total of 16 predictors identified from previous studies [11-13,18,27,28]. The calculated sample size was 143 patients. After accounting for a 30\% non-response rate, a total of 204 patients were recruited. A quota sampling method was used to recruit an equal proportion of male and female (102 each) HD patients.

\subsection{Research Instrument}

A semi-structured questionnaire was used to collect the patients' information including: (i) sociodemographic data; (ii) clinical data; (iii) BIA measurement; (iv) anthropometric measurements; (v) biochemical data; (vi) dietary intake assessment; and (vii) PEW diagnosis.

\subsection{Sociodemographic Data and Clinical Data}

Sociodemographic background (i.e., age, gender, ethnicity, marital status, education level, employment status, as well as monthly household income) were obtained via face-toface interview. Clinical data (i.e., year diagnosed with ESRD, dialysis vintage, presence of comorbidities, and blood pressure) were retrieved from both paper-based and electronic medical records at the respective HD centres.

\subsection{Nutritional Status Assessments}

\subsubsection{Bioelectrical Impedance Analysis Measurement (Index Test)}

In this study, PhA derived from BIA measurement was the index test [29]. BIA measurement was performed using a simple and portable multi-frequency $(5-1000 \mathrm{kHz})$ whole-body bioimpedance spectroscopy (BIS) (BCM, Fresenius Medical Care, Bad Homburg, Germany). The output parameters of this BIS device have been validated against gold standard reference methods of body composition measurements in previous studies [30]. Measurements were conducted before patients' HD treatment as per the manufacturer's guidelines [30] during the midweek dialysis session. This is because the ultrafiltration process during a dialysis session can affect fluid distribution in the body, which in turn has significant effects on the whole-body impedance measurements [31,32]. Patients were required to place themselves in a posterior recumbent position with disposable electrodes placed on 4 contact areas (i.e., metacarpophalangeal joint, wrist, metatarsophalangeal joint, and ankle) at the non-fistula access site (Supplementary Material Figure S1). The entire BIA measurement process took approximately $5 \mathrm{~min}$. A measurement quality value of $\geq 90 \%$ (a smooth, dome shape of a Cole-Cole plot) indicates a successful measurement [33,34]. The $\mathrm{PhA}$ value [arctangent $\left(\mathrm{X}_{\mathrm{C}} / \mathrm{R}\right) \times(180 / \pi)$ ], expressed in degree $\left(^{\circ}\right)$ was obtained from the BIA reading measured at the frequency of $50 \mathrm{kHz}$, in which the maximum reactance occurs, whereby the body cells are strongest in resisting the current, providing the highest $\mathrm{PhA}$ value [35]. The other BIA derived-parameters: body fat percentage (BF\%), measurement quality, overhydration $(\mathrm{OH})$, lean tissue index (LTI), fat tissue index (FTI), intracellular water (ICW), extracellular water (ECW), and body cell mass (BCM) were also recorded.

\subsubsection{Anthropometric Measurements}

Height, weight, mid-arm circumference (MAC), and triceps skinfold thickness (TSF) were measured in accordance with the International Society for the Advancement of Kinanthropometry (ISAK) by trained research dietitians [36]. Patients' heights were measured using a portable stadiometer (SECA-213, Hamburg, Germany), whereas pre- and postdialysis weight was measured using the weighing scale available at the respective dialysis units. In addition, post-dialysis weights during the past 3 months were retrieved from the 
patient's dialysis book to assess the extent of unintentional weight loss. Body mass index (BMI) was calculated using the formula of post-dialysis weight $(\mathrm{kg}) / \mathrm{height}\left(\mathrm{m}^{2}\right)$. MAC was measured using a non-extensible, Lufkin metal measuring tape (Apex Tool Group, LLC, Sparks, NC, USA), while TSF was measured using a Harpenden skinfold calliper (HSK-BI, British Indicators, West Sussex, UK). Both the MAC and TSF measurements were performed on the non-fistula arm of the patient. Mid-arm muscle circumference (MAMC) and corrected mid-arm muscle area (MAMA) for gender were then calculated using the following equations $[37,38]$ :

$$
\begin{gathered}
\text { MAMC }(\mathrm{cm})=[\mathrm{MAC}(\mathrm{cm})-\pi \times \operatorname{TSF}(\mathrm{cm})] \\
\text { MAMA }(\text { male })=\left[(\operatorname{MAC}(\mathrm{cm})-\pi \times \operatorname{TSF}(\mathrm{cm}))^{2} / 4 \pi\right]-10 \\
\text { MAMA }(\text { female })=\left[(\operatorname{MAC}(\mathrm{cm})-\pi \times \operatorname{TSF}(\mathrm{cm}))^{2} / 4 \pi\right]-6.5
\end{gathered}
$$

All measurements were taken twice, and the mean value was recorded. A third measurement was obtained when the difference between the first and second measurement exceeded $5 \%$ for the TSF measurement, or $1 \%$ for other measurements (i.e., height, weight, and MAC), as outlined in the ISAK protocol [36].

\subsubsection{Biochemical Data}

Patients' biochemical data (i.e., pre- and post-dialysis serum urea, pre-dialysis serum creatinine, serum albumin, and serum cholesterol) were obtained based on the latest routine blood result (i.e., within a month). Fasting blood samples were collected by the dialysis nurse prior to their dialysis session. Blood samples were then analysed by the respective inhouse hospital laboratories and external certified laboratories. Dialysis treatment adequacy $(\mathrm{Kt} / \mathrm{V})$, which measures urea removal during a patient's dialysis treatment, was calculated using the Daugirdas formula [39].

\subsubsection{Dietary Intake Assessment}

Diet records were collected for 3 days ( 1 dialysis day, 1 non-dialysis day, and 1 optional weekend) by trained research dietitians [38]. Standard household measurement tools were used to guide patients in estimating food and beverage portions. The total dietary energy intake (DEI) and dietary protein intake (DPI) were analysed using Nutritionist Pro Software version 4.0.0 (Axxya Systems, LLC, Stafford, TX, USA). The Nutrient Composition of Malaysian Foods [40], and Energy and Nutrient Composition of Food, Singapore, [41] were the main sources of food database references for food data entry into the software. The adequacy of energy and protein intake were interpreted based on the patient's ideal body weight (IBW) or adjusted body weight if the patient's weight was $<95 \%$ or $>115 \%$ of the IBW [42]. Implausible reported energy intake was determined using the Goldberg cut-off based on the ratio of the reported energy intake to the basal metabolic rate (EI $\left.\mathrm{I}_{\text {rep }}: \mathrm{BMR}\right)$ [43]. Patients' BMR was estimated using the Harris-Benedict equation [44]. A physical activity level of 1.3 was applied for BMR calculation [45]. Patients having an EI:BMR of $<0.8,0.8-2.0$, and $>2.0$ were classified as under-reporters, acceptable reporters, and over-reporters of energy intake, respectively.

\subsubsection{PEW Diagnosis according to the ISRNM Criteria (Reference Standard)}

The reference standard denotes the best available method to detect patients who have the outcome of interest [29]. Due to lack of a gold standard method to detect PEW among HD patients, the criteria proposed by the ISRNM expert panel served as the reference standard for PEW diagnosis among the HD patients. It consists of 4 main criteria: (i) body mass (BMI $<23 \mathrm{~kg} / \mathrm{m}^{2} ; \mathrm{BF} \%<10 \%$; unintentional weight loss over time: $5 \%$ over 3 months or $10 \%$ over 6 months), (ii) muscle mass (MAMC: reduction $>10 \%$ in relation to 50th percentile of reference population; reduced muscle mass: $5 \%$ over 3 months or $10 \%$ over 6 months), (iii) serum chemistry (serum albumin $<38 \mathrm{~g} / \mathrm{L}$; serum cholesterol $<2.59 \mathrm{mmol} / \mathrm{L}$ ), and (iv) dietary intake (unintentional low DPI $<0.8 \mathrm{~g} / \mathrm{kg} \mathrm{BW} /$ day; unintentional low $\mathrm{DEI}<25 \mathrm{kcal} / \mathrm{kg} \mathrm{BW} /$ day) [2]. Patients are diagnosed with PEW if they fulfil at least 3 out 
of the 4 criteria (at least 1 component in each of the listed criteria) [2]. The criteria proposed by ISRNM for PEW diagnosis are listed in the Supplementary Materials (Table S1).

\subsection{Statistical Analyses}

Data were analysed using the Statistical Package for Social Sciences (SPSS) software version 26.0 (IBM, Chicago, IL, USA). Continuous variables with normal distribution were presented as mean \pm standard deviation (SD), whereas skewed data were presented as median (q1-q3). Categorical variables were expressed in frequency $(n)$ and percentages $(\%)$. Normality assumption was checked using the Shapiro-Wilk test and visual inspection of the histogram.

There were a total of 8 variables, with missing data ranging from $1.3 \%$ to $9.9 \%$ for MAC $(n=2,1.3 \%)$, TSF $(n=3,2.0 \%)$, pre-dialysis serum urea $(n=3,2.0 \%)$, serum albumin $(n=4$, $2.6 \%)$, post-dialysis serum urea $(n=5,3.3 \%)$, current pre-dialysis serum creatinine $(n=6$, $3.9 \%)$, serum cholesterol $(n=7,4.6 \%)$, and past-3 months pre-dialysis serum creatinine $(n=15,9.9 \%)$. Missing data were handled using multiple imputation methods to provide unbiased estimates of the missing values, as well as to preserve the sample size required to achieve sufficient statistical power [46]. A total of 10 iterations were imputed [47] and the mean value was obtained to replace the missing values.

The Pearson product-moment correlation was used to determine the magnitude and direction of the bi-variate relationships between PhA with PEW criteria and body composition. An independent t-test and one-way ANOVA were used to examine the mean differences in PhA across patients' characteristics. Hierarchical multiple linear regression (MLR) was used to determine the predictors of PhA. Variables were entered sequentially into two blocks, Block 1: patients' characteristics, and Block 2: Block $1+$ nutritional parameters. Subsequently, logistic regression was performed to determine the odds ratio for PhA according to the PEW criteria.

A receiver-operating characteristics (ROC) curve analysis was used to determine diagnostic accuracy and establish the gender-specific cut-offs for PhA to detect PEW. The area under the curve (AUC) indicates the discriminative power of the test. An AUC of 0.5 indicates no discriminative power, $>0.5$ to $<0.7$ indicates poor discriminative power, 0.7 to $<0.8$ indicates acceptable discriminative power, $\geq 0.8$ to $<0.9$ indicates excellent discriminative power, and $\geq 0.9$ indicates outstanding discriminative power [48]. Statistical significance was set at $p<0.05$.

\section{Results}

\subsection{Patient Recruitment}

A total of 310 patients were approached but only 236 patients were eligible to participate in the study. The reasons for exclusion were: (i) dialysis vintage $<6$ months $(n=37)$, (ii) frail and severely ill $(n=25)$, (iii) visual impairment $(n=4)$, (iv) speech impairment $(n=2)$, and $(\mathrm{v})$ involved in clinical trial $(n=6)$. Out of the 236 eligible patients, a total number of 204 patients were successfully recruited (response rate $=86.4 \%$ ). Prior to final data analysis, 52 patients were excluded, attributable to energy misreporters $(n=18)$, missed BIA measurements $(n=11)$, and BIA measurement quality $<90 \%(n=23)$, resulting in a final number of 152 patients. The flowchart for patient screening and recruitment is as depicted in the Supplementary Materials (Figure S2).

\subsection{Patients' Characteristics}

The sociodemographic and clinical data are summarised Table 1 . The median age of the patients was 58.5 (50.0-65.8) years, ranging from 25 to 77 years old. There were $81(53.3 \%)$ males and $71(46.7 \%)$ females. The major ethnic group composition consisted of Malays (55.3\%), followed by Chinese (32.9\%), and Indians (11.8\%), which is a similar ethnic composition to the HD population in Klang Valley [49]. The majority of the patients received a secondary education $(46.7 \%)$, were married $(89.5 \%)$, unemployed $(74.3 \%)$, and had a monthly income of >RM1000 @ USD 237.71 (50.7\%). Hypertension (75.7\%), diabetes 
mellitus (34.9\%), and hyperlipidemia (30.9\%) were the three major comorbidities that co-existed among the HD patients. More than half (56.6\%) of the HD patients had at least two comorbid conditions. The median dialysis vintage was 56 (30.0-97.8) months. The majority of the patients were adequately dialysed $(84.2 \%)$ as indicated by the mean $\mathrm{Kt} / \mathrm{V}$ of $1.5 \pm 0.3$.

Table 1. Patients' Characteristics $(n=152)$.

\begin{tabular}{|c|c|c|c|}
\hline Variables & $n(\%)$ & Median (q1-q3) & Range \\
\hline Age (years) & & $58.5(50.0-65.8)$ & $25-77$ \\
\hline \multicolumn{4}{|l|}{ Gender } \\
\hline Male & $81(53.3)$ & & \\
\hline Female & $71(46.7)$ & & \\
\hline \multicolumn{4}{|l|}{ Ethnicity } \\
\hline Malay & $84(55.3)$ & & \\
\hline Chinese & $50(32.9)$ & & \\
\hline Indian & $18(11.8)$ & & \\
\hline \multicolumn{4}{|l|}{ Education level } \\
\hline Primary & $42(27.6)$ & & \\
\hline Secondary & $71(46.7)$ & & \\
\hline Tertiary & $39(25.7)$ & & \\
\hline \multicolumn{4}{|l|}{ Marital status } \\
\hline Single & $16(10.5)$ & & \\
\hline Married & $136(89.5)$ & & \\
\hline \multicolumn{4}{|l|}{ Employment } \\
\hline Employed & $39(25.7)$ & & \\
\hline Unemployed & $113(74.3)$ & & \\
\hline \multicolumn{4}{|l|}{ Monthly income } \\
\hline$\leq \mathrm{RM} 1000$ & $75(49.3)$ & & \\
\hline$>$ RM1000 & $77(50.7)$ & & \\
\hline \multicolumn{4}{|l|}{ Comorbidities $^{\text {a }}$} \\
\hline Hypertension & $115(75.7)$ & & \\
\hline Diabetes mellitus & $53(34.9)$ & & \\
\hline Hyperlipidemia & $47(30.9)$ & & \\
\hline Others $\mathrm{b}$ & $41(27.0)$ & & \\
\hline \multicolumn{4}{|l|}{ No of comorbidities } \\
\hline None & $15(9.9)$ & & \\
\hline One & $51(33.6)$ & & \\
\hline Two & 47 (30.9) & & \\
\hline$\geq$ Three & $39(25.7)$ & & \\
\hline Dialysis vintage (months) & & $56(30.0-97.8)$ & $6-272$ \\
\hline Dialysis adequacy $(\mathrm{Kt} / \mathrm{V})$ & & $1.5 \pm 0.3^{c}$ & $0.6-2.5$ \\
\hline Adequate $(\geq 1.2)$ & $128(84.2)$ & & \\
\hline Inadequate $(<1.2)$ & $24(15.8)$ & & \\
\hline
\end{tabular}

Data are expressed as $n(\%)$ or median (q1-q3). ${ }^{a}$ The sum of frequency for comorbidities exceeds the total number of HD patients because some patients have multiple comorbidities; ${ }^{b}$ Other major comorbidities denote cardiovascular disease, hepatitis B \& C, stroke, gastritis, asthma, gout, and hypothyroidism (refer to Supplementary Materials Figure S3 for more details); ${ }^{c}$ Continuous data with normal distribution are expressed as the mean \pm SD.

\subsection{Comparison of PhA across Patients' Characteristics}

The comparisons of PhA across patients' characteristics are depicted in the Supplementary Materials (Table S2). A significant lower PhA was observed in patients who are older, Chinese, have a lower education level and are unemployed $(p<0.05)$. Male patients had a significantly higher PhA compared to females $\left(4.62 \pm 0.82^{\circ}\right.$ vs. $3.92 \pm 0.88^{\circ}$; $p<0.001)$. Patients who have $\geq 3$ comorbidities were also seen to have a significantly lower PhA compared to those with only one comorbidity $\left(4.03 \pm 0.86^{\circ}\right.$ vs. $\left.4.59 \pm 0.96^{\circ} ; p=0.020\right)$.

\subsection{Correlations between PhA with PEW Criteria and Body Composition in HD Patients}

$\mathrm{PhA}$ was significantly correlated with the majority of the PEW sub-components according to the ISRNM $(p<0.05)$ (Supplementary Materials Table S3). For instance, PhA 
has a strong positive correlation with serum creatinine $(r=0.542, p<0.001)$, a moderate positive correlation with MAMC $(r=0.444, p<0.001)$, and a weak positive correlation with serum albumin $(r=0.283, p<0.001)$, BMI $(r=0.175, p=0.031)$, and serum cholesterol $(r=0.209, p=0.010)$. Contrarily, PhA has a moderate negative correlation with $\mathrm{BF} \%$ $(r=-0.382, p<0.001)$. However, no significant correlation was observed between PhA with unintentional weight loss $(r=0.093, p=0.255)$, DEI $(r=0.074, p=0.362)$ and DPI $(r=0.057, p=0.484)$. In addition, PhA was significantly correlated with body composition parameters $(p<0.05)$ (Supplementary Materials Table S3). For instance, PhA has a strong positive correlation with a LTI $(r=0.718, p<0.001)$, ICW $(r=0.658, p<0.001)$, and BCM $(r=0.690, p<0.001)$, and a weak positive correlation with ECW $(r=0.251, p=0.002)$. On the other hand, PhA has a moderate negative correlation with $\mathrm{OH}(r=-0.420, p<0.001)$ and a weak negative correlation with a FTI $(r=-0.160, p=0.048)$.

\subsection{Predictors of PhA in HD Patients}

The hierarchical MLR analysis results are presented in Table 2. In Block 1, patients' characteristics accounted for a significant $39.4 \%$ of the variance in $\operatorname{PhA}\left(R^{2}=0.394\right.$, $\mathrm{F}(12,139)=7.527, p<0.001)$. PhA could be predicted by age $(\beta=-0.395, p=<0.001)$, gender $\left(\beta_{\text {female }}=-0.374, p<0.001\right)$, ethnicity $\left(\beta_{\text {Indian }}=-0.189, p=0.010\right)$, and dialysis vintage $(\beta=-0.154)$.

Table 2. Predictors of PhA in HD Patients $(n=152)$.

\begin{tabular}{|c|c|c|c|c|}
\hline \multirow{3}{*}{ Variables } & \multicolumn{4}{|c|}{ Model 1} \\
\hline & \multicolumn{2}{|c|}{ Block 1} & \multicolumn{2}{|c|}{ Block 2} \\
\hline & $\beta$ & $\mathbf{R}^{2}$ & $\beta$ & $R^{2}$ \\
\hline Age & $-0.395^{* * *}$ & 0.394 & $-0.199 *$ & 0.602 \\
\hline \multicolumn{5}{|l|}{ Gender a } \\
\hline Female & $-0.374 * * *$ & & -0.090 & \\
\hline \multicolumn{5}{|l|}{ Ethnicity $\mathrm{b}$} \\
\hline Chinese & -0.058 & & -0.050 & \\
\hline Indian & $-0.189 *$ & & -0.044 & \\
\hline \multicolumn{5}{|l|}{ Education level ${ }^{\mathrm{c}}$} \\
\hline Secondary & 0.047 & & -0.014 & \\
\hline Tertiary & -0.023 & & -0.028 & \\
\hline \multicolumn{5}{|l|}{ Marital status ${ }^{d}$} \\
\hline Married & 0.039 & & -0.007 & \\
\hline \multicolumn{5}{|l|}{ Employment $\mathrm{e}$} \\
\hline Unemployed & -0.079 & & -0.054 & \\
\hline \multicolumn{5}{|l|}{ Monthly income ${ }^{f}$} \\
\hline$\leq \mathrm{RM} 1000$ & 0.060 & & 0.051 & \\
\hline \multicolumn{5}{|l|}{ Clinical data } \\
\hline No. of comorbidities & -0.101 & & -0.079 & \\
\hline Dialysis vintage (months) & $-0.154 *$ & & -0.089 & \\
\hline Dialysis adequacy $(\mathrm{Kt} / \mathrm{V})$ & -0.011 & & 0.049 & \\
\hline \multicolumn{5}{|l|}{ Body mass } \\
\hline $\operatorname{BMI}\left(\mathrm{kg} / \mathrm{m}^{2}\right)$ & - & & $0.266^{*}$ & \\
\hline $\mathrm{BF}(\%)$ & - & & $-0.334^{* * *}$ & \\
\hline Unintentional weight loss (\%) & - & & 0.007 & \\
\hline \multicolumn{5}{|l|}{ Muscle mass } \\
\hline MAMC $(\mathrm{cm})$ & - & & 0.111 & \\
\hline Serum creatinine (umol/L) & - & & $0.229^{* *}$ & \\
\hline \multicolumn{5}{|l|}{ Serum chemistry } \\
\hline Albumin (g/L) & - & & $0.205^{* *}$ & \\
\hline Cholesterol $(\mathrm{mmol} / \mathrm{L})$ & - & & $0.171^{* *}$ & \\
\hline \multicolumn{5}{|l|}{ Dietary intake } \\
\hline DEI (kcal/kg BW/day) & - & & 0.025 & \\
\hline DPI (g/kg BW/day) & - & & 0.036 & \\
\hline
\end{tabular}

Reference group: ${ }^{\mathrm{a}}$ Male, ${ }^{\mathrm{b}}$ Malay, ${ }^{\mathrm{c}}$ Primary education, ${ }^{\mathrm{d}}$ Single, ${ }^{\mathrm{e}}$ Employed, ${ }^{\mathrm{f}}$ Monthly income $>$ RM 1000 Abbreviations: BMI, body mass index; BF, body fat; MAMC, mid-arm muscle circumference; DEI, dietary energy intake; DPI, dietary protein intake. Model 1: Hierarchical Multiple Regression Model for PhA; Block 1: Patients' characteristics; Block 2: Block $1+$ nutritional parameters; ${ }^{*} p<0.05,{ }^{* *} p<0.01,{ }^{* * *} p<0.001$. 
In Block 2, the addition of nutritional markers accounted for an additional $20.8 \%$ of variance in $\mathrm{PhA}\left(\Delta \mathrm{R}^{2}=0.208, \Delta \mathrm{F}(9,130)=7.565, p<0.001\right)$. BMI $(\beta=0.266, p=0.018), \mathrm{BF} \%$ $(\beta=-0.334, p<0.001)$, pre-dialysis serum creatinine $(\beta=0.229, p=0.003)$, serum albumin $(\beta=0.205, p=0.001)$, and serum cholesterol $(\beta=0.171, p=0.005)$ were significant predictors of PhA. Age $(\beta=0.199, p=0.017)$ remained as a significant independent predictor of $\mathrm{PhA}$ after adjusting for nutritional markers. On the other hand, the significant effects of gender, ethnicity, and dialysis vintage were lost after the addition of nutritional markers into the model $(p>0.05)$. In summary, PhA in HD patients could be predicted based on the regression model equation as stated: $\mathrm{PhA}=0.435-(0.016 \times$ age in years $)+(0.056 \times \mathrm{BMI})$ $+(-0.034 \times \mathrm{BF} \%)+(0.001 \times$ pre-dialysis serum creatinine $)+(0.054 \times$ serum albumin $)+$ $(0.153 \times$ serum cholesterol $)$.

\subsection{Associations of PhA and PEW Criteria in HD Patients}

PEW was evident in $21.1 \%$ of the HD patients as per the ISRNM criteria. The adjusted odds ratio for PhA, as per the PEW criteria, is depicted in Figure 1. Individual PEW criteria were dichotomised according to the cut-off proposed by the ISRNM. PhA is a significant predictor of PEW after adjusting for patients' characteristics (adjOR: 0.308, 95\% CI $=0.156$, $0.608, p=0.001)$. Patients with lower PhA had 3.2 times higher odds to be diagnosed with PEW (met at least 3 out of the 4 criteria) (adjOR $=0.308,95 \% C I=0.156,0.608$ ). However, only 2 out 7 of the PEW criteria examined could be significantly predicted by PhA, namely MAMC reduction $>10 \%(p=0.002)$ and serum albumin $<38 \mathrm{~g} / \mathrm{L}(p=0.016)$. An increase in one unit of PhA could significantly reduce the odds of having serum albumin $<38 \mathrm{~g} / \mathrm{L}$ by $59.1 \%$ (adjOR $=0.409,95 \% \mathrm{CI}=0.198-0.845$ ), followed by a $63.1 \%$ reduction in the odds of having a MAMC reduction $>10 \%($ adjOR $=0.369,95 \% \mathrm{CI}=0.198-0.690)$.

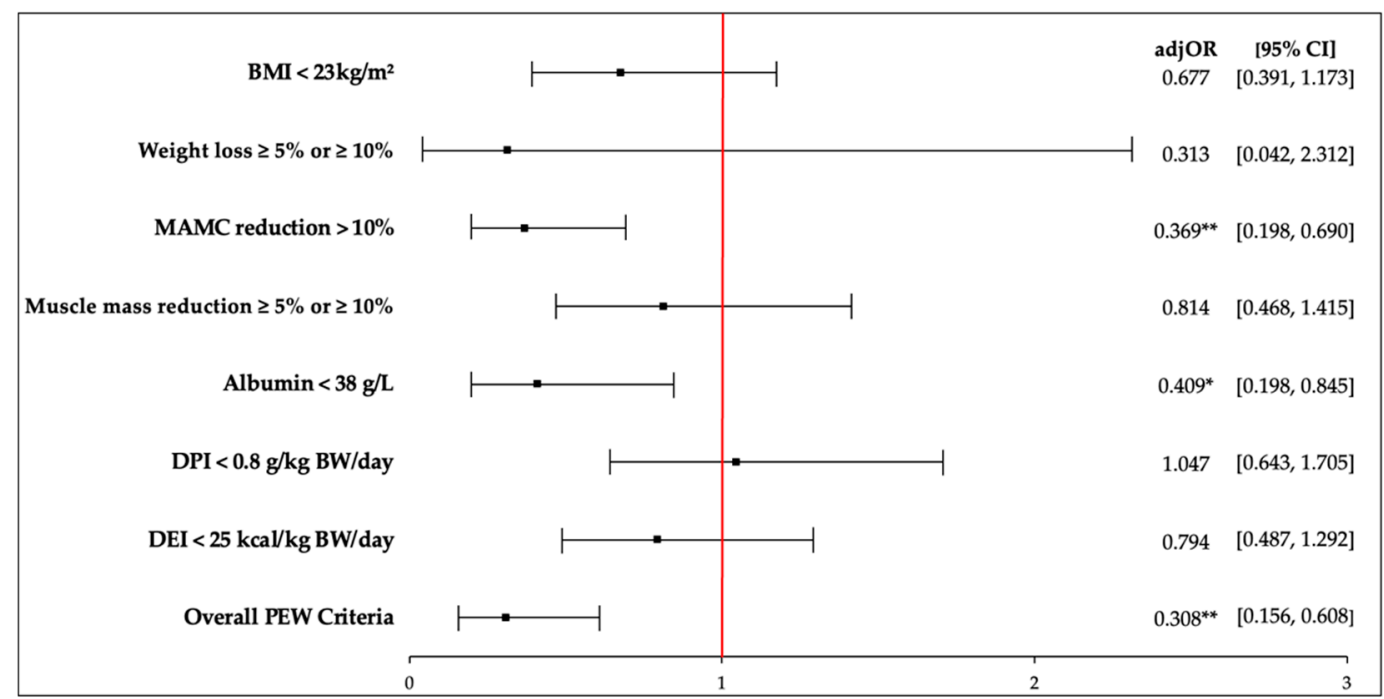

Figure 1. Forest plot for adjusted odds ratio of PhA as per PEW criteria according to ISRNM. Abbreviations: adjOR, adjusted odds ratio; BMI, body mass index; MAMC, mid-arm muscle circumference; DPI, dietary protein intake; DEI, dietary energy intake; PEW, protein energy wasting. OR was adjusted for age, gender, ethnicity, education level, marital status, employment, monthly income, comorbidities, dialysis vintage, and Kt/V. The red line represents odds ratio value of 1 (no association). Serum cholesterol and body fat percentage were not included as the expected frequency had less than five representative cases. ${ }^{*} p<0.05,{ }^{* *} p<0.01$.

\subsection{PhA Cut-Offs to Detect PEW in HD Patients}

PhA was significantly lower in the PEW group $\left(3.75^{\circ} \pm 0.90\right)$ compared to the nonPEW group $\left(4.43^{\circ} \pm 0.87\right)(p<0.001)$. The PhA cut-offs for detecting PEW and their diagnostic accuracy measures are depicted in Figure 2 and Table 3. ROC curve analysis showed that PhA had a significant acceptable to excellent discriminative performance in 
detecting PEW among HD patients $\left(\right.$ adjAUC $_{\text {overall }}=0.746, p<0.001 ;$ adjAUC $_{\text {male }}=0.809$, $p<0.001$; adjAUC $\mathrm{female}=0.719, p=0.007)$. The overall PhA cut-off for PEW diagnosis was $4.11^{\circ}$ (sensitivity $=62.5 \%$, specificity $=61.7 \%$ ). On the other hand, the PhA cut-off for PEW diagnosis in male patients was $4.26^{\circ}$ (sensitivity $=68.8 \%$, specificity $=67.7 \%$ ), whereas female patients had a lower PhA cut-off at $3.30^{\circ}$ (sensitivity $=68.8 \%$, specificity $=85.5 \%$ ). The overall model quality was $>0.5$, representing a good model prediction as shown in the Supplementary Materials (Figure S4).

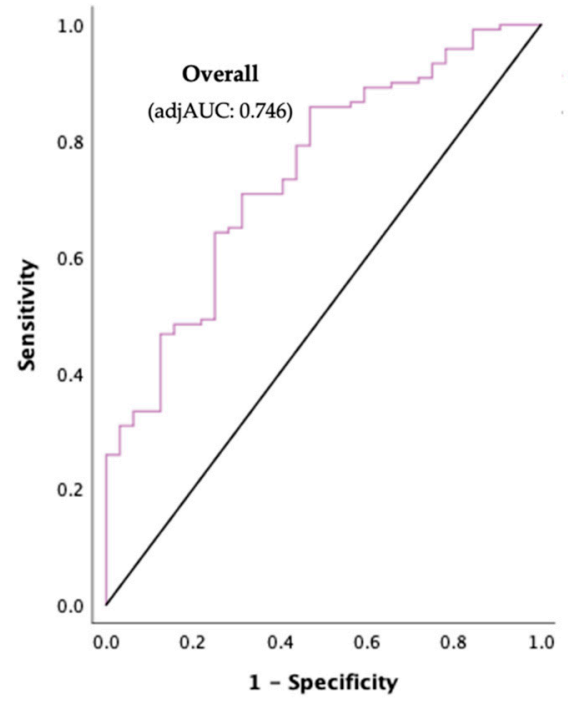

(a)

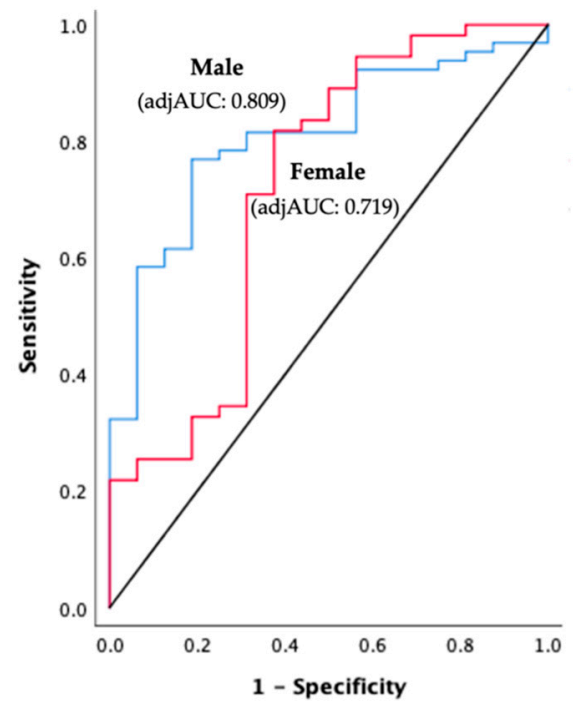

(b)

Figure 2. (a) Overall ROC curve analysis for PhA to detect PEW among HD patients; (b) ROC curve analysis for PhA according to gender to detect PEW among HD patients. Abbreviations: ROC, receiver operating characteristics; adjAUC, area under the curve adjusted for age, dialysis vintage, comorbidities, measurement quality, and overhydration.

Table 3. Diagnostic Accuracy of PhA to detect PEW in HD patients $(n=152)$.

\begin{tabular}{cccccc}
\hline & PhA Cut-Off $\left({ }^{\circ}\right)$ & adjAUC & Sensitivity (\%) & Specificity (\%) & $p$-Value \\
\hline Overall $(n=152)$ & 4.11 & 0.746 & 62.5 & 61.7 & $<0.001$ \\
Male $(n=81)$ & 4.26 & 0.809 & 68.8 & 67.7 & $<0.001$ \\
Female $(n=71)$ & 3.30 & 0.719 & 68.8 & 85.5 & 0.007
\end{tabular}

Abbreviations: PhA, phase angle; adjAUC, area under the curve adjusted for age, dialysis vintage, comorbidities, measurement quality, and overhydration. Data was analysed using Receiver Operating Characteristics curve analysis.

\section{Discussion}

This study provides a comprehensive view of knowledge pertaining to patients' characteristics using PhA and its prediction for PEW diagnosis. As shown in this study, PhA declined with aging, and this might be due to the profound age-related changes in body composition including skeletal muscle loss (reactance) [50] and fat mass accumulation (resistance) [20]. Furthermore, our study also suggests that the deterioration of PhA (i.e., cell membrane integrity) might also occur due to the effect of aging per se [51], irrespective of body composition changes (see Block 2 in Table 2). In line with previous studies, the differences in $\mathrm{PhA}$ across gender, ethnicity, and dialysis vintage were also found to be confounded by body composition (see Block 2 in Table 2) [18,25,52].

Despite the PhA disparity across patients' characteristics in different populations $[11-13,15]$, the external validity of $\mathrm{PhA}$ in detecting PEW among the HD population has been extended to a multi ethnicity population. In this study, PhA was found to be an independent predictor of PEW in HD patients (adjOR: 0.308, $p=0.001$ ). As expected, patients with PEW had a lower PhA compared to their non-PEW counterparts $[11,15]$. 
PEW is a pathological condition accompanied with depletion of fat and muscle stores the body [2] which disrupts the normal function of healthy cells by altering their membrane integrity and function [20]. Surprisingly, although PhA correlated with the majority of the nutritional markers, it failed to predict most of the PEW criteria using the ISRNM cut-offs. Since the ISRNM cut-offs are derived from the American population, its utility in other countries has been disputed [53]. For instance, there was a drastic difference in the number of HD patients diagnosed with PEW using the ISRNM criteria (13.3\%) compared to the Subjective Global Assessment (80.0\%) [54]. In this study, only $0.7 \%(1 / 152)$ of the HD patients fulfilled the criteria of body fat percentage $<10 \%$, and $2.0 \%(3 / 152)$ fulfilled the criteria of having serum cholesterol $<2.59 \mathrm{mmol} / \mathrm{L}$. This might reflect the unequal contribution of individual ISRNM criterion towards a PEW diagnosis, and imply the need to revisit the use of these cut-offs in non-Caucasians. Interestingly, PhA seems to be less sensitive to reflect dietary energy and protein intake in the current study. This relationship could be attenuated owing to regression dilution bias because of day-to-day variation in dietary intake $[55,56]$. However, this did not confiscate the discriminative ability of PhA to detect PEW among HD patients in both current and previous studies [12,15].

The optimal PhA cut-off $\left(4.11^{\circ}\right)$ to detect PEW among multi-ethnic HD patients in this study was within the range of values found in previous studies. Nonetheless, it is worth noting that a wide range in $\mathrm{PhA}$ cut-offs were reported $\left(3.7-4.64^{\circ}\right)$ [11-15]. This could be due to a number of reasons including the differences in age distribution, gender ratio, ethnic groups, as well as the type of BIA device used (Supplementary Materials Table S4). For instance, the PhA cut-off proposed by Leal-Escobar et al. was the highest $\left(4.64^{\circ}\right)$ compared to other studies, and this could be explained by the relatively lower body fat percentage and higher muscle mass percentage of the Western nation compared to Asian [11,57]. Correspondingly, sub-group analysis in this study demonstrated ethnic differences in $\mathrm{PhA}$ cut-offs for a PEW diagnosis (Supplementary Materials Table S5). Furthermore, previous studies were conducted among populations with vast age ranges (i.e., mean age of 36.5 to 68.0 years old in the literature) [11-15] and this might contribute to the variation in PhA. In addition, the measurement frequency of the BIA device used (e.g., 5, 50, or $250 \mathrm{kHz}$ ) also affects PhA [58]. Although multi-frequency measurements show a better ability to estimate extracellular fluid volume (i.e., hydration status) than single-frequency measurement, good agreement was found for intracellular fluid volume (i.e., nutritional status) [59]. To date, $50 \mathrm{kHz}$ is ideal for PhA measurements [35]. Therefore, healthcare professionals should consider the type and measurement frequency of BIA devices based on the purpose of assessment. Furthermore, this study implies the need for gender-specific PhA cut-offs to detect PEW in HD patients, attributed to the difference in fat and muscle mass composition. The current study found that males have a higher PhA cut-off $\left(4.26^{\circ}\right)$ compared to females $\left(3.30^{\circ}\right)$. This is because males have a higher proportion of muscle mass (reactance) and lower body fat percentage (resistance) compared to females with the same BMI [60].

The sensitivity $(68.8 \%)$ of the gender-specific PhA cut-off found in this study was slightly lower compared to previous studies (ranging from $77.7 \%$ to $86.4 \%$ ) $[11,13,15]$. This could be due to the different methods used to select the most optimal PhA cut-off point on the ROC curve [61], which has not been reported in previous studies. In this study, both sensitivity (68.8\%) and specificity (ranging from 67.7\% to 85.5\%) indices were maximised to correctly identify those patients with PEW (true positive) and without PEW (true negative) [61]. Notably, specificity was prioritised in this study to minimise false-negative results which can cause detrimental outcomes due to misdiagnosis.

This study was subjected to several limitations that could be addressed in forthcoming studies. In light of the cross-sectional study design, the predictive validity of PhA to diagnose PEW cannot be established. Thus, longitudinal predictive research could be employed to strengthen the validity of the study findings. Moreover, a non-probability sampling method was used, hence, the results of this study could not be generalised to the entire Malaysian population. The predictive accuracy of PhA might be slightly diminished by age, gender, and ethnic differences in body composition. Therefore, future studies 
should consider establishing age-, ethnicity-, and gender-specific PhA cut-offs to further improve on the predictive accuracy. In addition, inter-device validation studies are also required to determine the agreement in PhA measurements for PEW diagnosis in HD patients. Despite the limitations, this study provides the evidence to support the use of PhA to detect PEW in multi-ethnic HD populations. Furthermore, we also provide novel insights on the relevance of using gender-specific PhA cut offs for PEW diagnosis in HD patients.

\section{Conclusions}

$\mathrm{PhA}$ appears as a pragmatic and valid biomarker which allows for the rapid detection of PEW among multi-ethnic HD patients in a clinical setting. PhA cut-offs, at $4.26^{\circ}$ for male and $3.30^{\circ}$ for female, had acceptable to excellent discriminative performance in detecting PEW among multi-ethnic HD patients. Healthcare professionals should consider the use of $\mathrm{PhA}$ measurements in making data-driven decisions to improve the quality of patient care.

Supplementary Materials: The following are available online at https:/ / www.mdpi.com/article/10 .3390/diagnostics11101745/s1, Figure S1: Body Composition Measurement using Fresenius Bioelectrical Impedance Spectroscopy. Table S1: Criteria Proposed by ISRNM to Diagnose PEW, Figure S2: Flowchart of Patient Recruitment, Figure S3: Other Major Comorbidities, Table S2: Comparison of PhA across Patients' Characteristics, Table S3: Correlations between PhA with PEW Criteria and Body Composition in HD Patients, Figure S4: Overall Model Quality, Table S4: Comparisons of Previous Studies using PhA for PEW Diagnosis, Table S5: Sub-group Analysis for Diagnostic Accuracy of PhA according to Ethnicity to detect PEW in HD patients.

Author Contributions: Conceptualisation, C.-K.-M.L., J.-H.L., and Z.A.M.D.; methodology, C.-K.M.L., J.-H.L., and Z.A.M.D.; validation, Z.A.M.D.; formal analysis, C.-K.-M.L. and J.-H.L.; data collection, C.-K.-M.L., J.-H.L., and I.I.; data curation, C.-K.-M.L.; writing-original draft preparation, C.-K.-M.L.; writing-review and editing, Z.A.M.D., J.-H.L., Y.-M.C., N.F.Z., and R.Y.; supervision, Z.A.M.D.; project administration, C.-K.-M.L. All authors have read and agreed to the published version of the manuscript.

Funding: This research received no external funding. C.-K.-M.L. received financial support as a graduate research fellow from Universiti Putra Malaysia. The APC was supported by Universiti Putra Malaysia. All other authors have no relevant financial interest to declare.

Institutional Review Board Statement: The study was conducted according to the guidelines of the Declaration of Helsinki, and approved by the Ethic Committee for Research Involving Human Subjects of Universiti Putra Malaysia (JKEUPM-2019-064, approved date 1 February 2019).

Informed Consent Statement: Written informed consent was obtained from all participants involved in the study.

Data Availability Statement: The data presented in the study are available on request from the corresponding author.

Acknowledgments: The authors would like to express their sincere appreciation to the dialysis managers, nurses, and staffs at all the study sites who lent a helping hand during the data collection process. Special thanks to all the respondents who participated in this study. We would also like to acknowledge Nicola Elizabeth Burt for proofreading the manuscript.

Conflicts of Interest: The authors have no conflict of interest to declare.

\section{References}

1. Piccoli, G.B.; Moio, M.R.; Fois, A.; Sofronie, A.; Gendrot, L.; Cabiddu, G.; D'Alessandro, C.; Cupisti, A. The Diet and Haemodialysis Dyad: Three Eras, Four Open Questions and Four Paradoxes. A Narrative Review, Towards a Personalized, Patient-Centered Approach. Nutrients 2017, 9, 372. [CrossRef]

2. Fouque, D.; Kalantar-Zadeh, K.; Kopple, J.; Cano, N.; Chauveau, P.; Cuppari, L.; Franch, H.; Guarnieri, G.; Ikizler, T.A.; Kaysen, G.; et al. A proposed nomenclature and diagnostic criteria for protein-energy wasting in acute and chronic kidney disease. Kidney Int. 2008, 73, 391-398. [CrossRef]

3. Dai, L.; Mukai, H.; Lindholm, B.; Heimbürger, O.; Barany, P.; Stenvinkel, P.; Qureshi, A.R. Clinical global assessment of nutritional status as predictor of mortality in chronic kidney disease patients. PLoS ONE 2017, 12, e0186659. [CrossRef] 
4. Hyun, Y.Y.; Lee, K.B.; Han, S.H.; Kim, Y.; Kim, Y.H.; Lee, S.W.; Oh, Y.K.; Chae, D.W.; Ahn, C. Nutritional Status in Adults with Predialysis Chronic Kidney Disease: KNOW-CKD Study. J. Korean Med. Sci. 2017, 32, 257. [CrossRef] [PubMed]

5. Carrero, J.J.; Thomas, F.; Nagy, K.; Arogundade, F.; Avesani, C.M.; Chan, M.; Chmielewski, M.; Cordeiro, A.C.; EspinosaCuevas, A.; Fiaccadori, E.; et al. Global Prevalence of Protein-Energy Wasting in Kidney Disease: A Meta-Analysis of Contemporary Observational Studies From the International Society of Renal Nutrition and Metabolism. J. Ren. Nutr. 2018, 28, 380-392. [CrossRef]

6. $\quad$ Ikizler, T.A.; Cano, N.J.; Franch, H.; Fouque, D.; Himmelfarb, J.; Kalantar-Zadeh, K.; Kuhlmann, M.K.; Stenvinkel, P.; TerWee, P.; Teta, D.; et al. Prevention and treatment of protein energy wasting in chronic kidney disease patients: A consensus statement by the International Society of Renal Nutrition and Metabolism. Kidney Int. 2013, 84, 1096-1107. [CrossRef] [PubMed]

7. Obi, Y.; Qader, H.; Kovesdy, C.P.; Kalantar-Zadeh, K. Latest consensus and update on protein-energy wasting in chronic kidney disease. Curr. Opin. Clin. Nutr. Metab. Care 2015, 18, 254-262. [CrossRef] [PubMed]

8. Sarav, M.; Kovesdy, C.P. Protein Energy Wasting in Hemodialysis Patients. Clin. J. Am. Soc. Nephrol. 2018, 13, 1558-1560. [CrossRef] [PubMed]

9. Bello, A.K.; Levin, A.; Lunney, M.; Osman, M.A.; Ye, F.; Ashuntantang, G.; Bellorin-Font, E.; Benghanem, G.M.; Ghnaimat, M.; Harden, P.; et al. Global Kidney Health Atlas: A Report by the International Society of Nephrology on the Global Burden of End-Stage Kidney Disease and Capacity for Kidney Replacement Therapy and Conservative Care across World Countries and Regions; International Society of Nephrology: Brussels, Belgium, 2019; p. 70.

10. Chao, C.T.; Tang, C.H.; Cheng, R.W.Y.; Wang, M.Y.H.; Hung, K.Y. Protein-energy wasting significantly increases healthcare utilization and costs among patients with chronic kidney disease: A propensity-score matched cohort study. Curr. Med. Res. Opin. 2017, 33, 1705-1713. [CrossRef] [PubMed]

11. Leal Escobar, G.; Osuna Padilla, I.A.; Cano Escobar, B.; Moguel González, B.; Pérez Grovas, H.A.; Ruiz Ubaldo, S. Phase angle and mid arm circumference as predictors of protein energy wasting in renal replacement therapy patients. Nutr. Hosp. 2019, $36,633-639$.

12. Ruperto, M.; Sánchez-Muniz, F.J.; Barril, G. Predictors of protein-energy wasting in haemodialysis patients: A cross-sectional study. J. Hum. Nutr. Diet. 2014, 29, 38-47. [CrossRef] [PubMed]

13. Tan, R.S.; Liang, D.H.; Liu, Y.; Zhong, X.S.; Zhang, D.S.; Ma, J. Bioelectrical Impedance Analysis-Derived Phase Angle Predicts Protein-Energy Wasting in Maintenance Hemodialysis Patients. J. Ren. Nutr. 2019, 29, 295-301. [CrossRef] [PubMed]

14. Saitoh, M.; Ogawa, M.; Kondo, H.; Suga, K.; Takahashi, T.; Itoh, H.; Tabata, Y. Bioelectrical impedance analysis-derived phase angle as a determinant of protein-energy wasting and frailty in maintenance hemodialysis patients: Retrospective cohort study. BMC Nephrol. 2020, 21, 438. [CrossRef]

15. Zhou, H.; Yao, W.; Pan, D.; Sun, G. Predicational ability of phase angle on protein energy wasting in kidney disease patients with renal replacement therapy: A cross-sectional study. Food Sci. Nutr. 2021. [CrossRef] [PubMed]

16. Pupim, L.B.; Martin, C.J.; Ikizler, T.A. Assessment of Protein and Energy Nutritional Status. In Nutritional Management of Renal Disease, 3rd ed.; Kopple, J.D., Kalantar-Zadeh, K., Massry, S.G., Eds.; Academic Press: San Diego, CA, USA, 2013 ; p. 144. ISBN 978-0-12-391934-2.

17. Your Body and You: A Guide to Phase Angle-InBody USA. Available online: https://inbodyusa.com/blogs/inbodyblog/yourbody-and-you-a-guide-to-phase-angle/ (accessed on 29 June 2021).

18. Barbosa-Silva, M.C.; Barros, A.J.D.; Wang, J.; Heymsfield, S.B.; Pierson, R.N., Jr. Bioelectrical impedance analysis: Population reference values for phase angle by age and sex. Am. J. Clin. Nutr. 2005, 82, 49-52. [CrossRef] [PubMed]

19. Tanaka, S.; Ando, K.; Kobayashi, K.; Seki, T.; Hamada, T.; Machino, M.; Ota, K.; Morozumi, M.; Kanbara, S.; Ito, S.; et al. Low Bioelectrical Impedance Phase Angle Is a Significant Risk Factor for Frailty. BioMed Res. Int. 2019, 2019, 1-7. [CrossRef]

20. Norman, K.; Stobäus, N.; Pirlich, M.; Bosy-Westphal, A. Bioelectrical phase angle and impedance vector analysis-Clinical relevance and applicability of impedance parameters. Clin. Nutr. 2012, 31, 854-861. [CrossRef]

21. Zouridakis, A.; Simos, Y.V.; Verginadis, I.I.; Charalabopoulos, K.; Ragos, V.; Dounousi, E.; Boudouris, G.; Karkabounas, S.; Evangelou, A.; Peschos, D. Correlation of bioelectrical impedance analysis phase angle with changes in oxidative stress on end-stage renal disease patients, before, during, and after dialysis. Ren. Fail. 2016, 38, 738-743. [CrossRef]

22. Gupta, D.; Lammersfeld, C.A.; Vashi, P.G.; King, J.; Dahlk, S.L.; Grutsch, J.F.; Lis, C.G. Bioelectrical impedance phase angle as a prognostic indicator in breast cancer. BMC Cancer 2008, 8. [CrossRef]

23. Fernandes, S.A.; de Mattos, A.A.; Tovo, C.V.; Marroni, C.A. Nutritional evaluation in cirrhosis: Emphasis on the phase angle. World J. Hepatol. 2016, 8, 1205. [CrossRef]

24. Gerken, A.L.H.; Rohr-Kräutle, K.K.; Weiss, C.; Seyfried, S.; Reissfelder, C.; Vassilev, G.; Otto, M. Handgrip Strength and Phase Angle Predict Outcome After Bariatric Surgery. Obes. Surg. 2020, 31, 200-206. [CrossRef] [PubMed]

25. Jensen, B.; Moritoyo, T.; Kaufer-Horwitz, M.K.; Peine, S.; Norman, K.; Maisch, M.J.; Matsumoto, A.; Masui, Y.; VelázquezGonzález, A.; Domínguez-García, J.; et al. Ethnic differences in fat and muscle mass and their implication for interpretation of bioelectrical impedance vector analysis. Appl. Physiol. Nutr. Metab. 2019, 44, 619-626. [CrossRef] [PubMed]

26. Von Elm, E.; Altman, D.; Egger, M.; Pocock, S.; Gøtzsche, P.; Vandenbroucke, J. The Strengthening the Reporting of Observational Studies in Epidemiology (STROBE) Statement: Guidelines for reporting observational studies. Int. J. Surg. 2007, 12, 1495-1499. [CrossRef] [PubMed] 
27. Chertow, G.M.; Lazarus, J.M.; Lew, N.L.; Ma, L.; Lowrie, E.G. Bioimpedance norms for the hemodialysis population. Kidney Int. 1997, 52, 1617-1621. [CrossRef]

28. Abad, S.; Sotomayor, G.; Vega, A.; Pérez de José, A.; Verdalles, U.; Jofré, R.; López-Gómez, J.M. The phase angle of the electrical impedance is a predictor of long-term survival in dialysis patients. Nefrologia 2011, 31, 670-676. [CrossRef]

29. Leeflang, M.M.; Deeks, J.J.; Gatsonis, C.; Bossuyt, P.M.; Cochrane Diagnostic Test Accuracy Working Group. Systematic reviews of diagnostic test accuracy. Ann. Intern. Med. 2008, 149, 889-897. [CrossRef]

30. BCM-Body Composition Monitor; Fresenius Medical Care: Hong Kong, 2021; pp 1-7. Available online: http:/ /www.fmc-my. com/pdf/body_composition_monitor/Body\%20Composition\%20Monitor.pdf (accessed on 29 June 2021).

31. Keane, D.F.; Baxter, P.; Lindley, E.; Moissl, U.; Pavitt, S.; Rhodes, L.; Wieskotten, S. The Body Composition Monitor: A Flexible Tool for Routine Fluid Management Across The Haemodialysis Population. Biomed. Phys. Eng. Express 2017, 3, 035017. [CrossRef]

32. Abbas, S.R.; Zhu, F.; Kaysen, G.A.; Kotanko, P.; Levin, N.W. Effect Of Change In Fluid Distribution In Segments In Hemodialysis Patients At Different Ultrafiltration Rates On Accuracy Of Whole Body Bioimpedance Measurement. J. Appl. Physiol. 2014, 116, 1382-1389. [CrossRef]

33. Chen, H.S.; Lee, K.C.; Cheng, C.T.; Hou, C.C.; Liou, H.H.; Lin, C.J.; Lim, P.S. Application of Bioimpedance Spectroscopy in Asian Dialysis Patients (ABISAD): Serial follow-up and dry weight evaluation. Clin. Kidney J. 2012, 6, 29-34. [CrossRef]

34. Hou, G.C.; Gan, H.; Sun, X.; Li, J. Use of body composition measurements to guide the assessment of dry weight in anuric dialysis patients: Improvements in blood pressure control. Biochem. Biophys. Rep. 2019, 17, 191-196. [CrossRef]

35. Kumar, S.; Dutt, A.; Hemraj, S.; Bhat, S.; Manipadybhima, B. Phase Angle Measurement in Healthy Human Subjects through Bio-Impedance Analysis. Iran J. Basic Med. Sci. 2012, 15, 1180-1184. [PubMed]

36. Stewart, A.; Marfell-Jones, M.; Olds, T.; de Ridder, H. International Standards for Anthropometric Assessment; International Society for the Advancement of Kinanthropometry: Lower Hutt, New Zealand, 2011.

37. Heymsfield, S.B.; McManus, C.; Smith, J.; Stevens, V.; Nixon, D.W. Anthropometric measurement of muscle mass: Revised equations for calculating bone-free arm muscle area. Am. J. Clin. Nutr. 1982, 36, 680-690. [CrossRef]

38. Clinical practice guidelines for nutrition in chronic renal failure. K/DOQI National Kidney Foundation. Am. J. Kidney Dis. 2000, 35, S1-S140. Available online: https:/ / www.kidney.org/sites/default/files/docs/kdoqi2000nutritiongl.pdf (accessed on 18 September 2021).

39. Levy, J.; Brown, E.; Lawrence, A. Oxford Handbook of Dialysis, 4th ed.; Oxford University Press: Oxford, UK, 2016 ; p. 166.

40. Tee, E.S.; Mohd Ismail, N.; Mohd Nasir, A.; Khatijah, I. Nutrient Composition of Malaysian Foods, 4th ed.; Institute for Medical Research Malaysia: Kuala Lumpur, Malaysia, 1997; ISBN 978-967-99909-8-0.

41. Singapore Health Promotion Board. Energy \& Nutrient Composition of Food. Available online: https://focos.hpb.gov.sg/ eservices/ENCF/ (accessed on 30 June 2021).

42. Ikizler, T.A.; Burrowes, J.D.; Byham-Gray, L.D.; Campbell, K.L.; Carrero, J.J.; Chan, W.; Fouque, D.; Friedman, A.N.; Ghaddar, S.; Goldstein-Fuchs, D.J.; et al. KDOQI Nutrition in CKD Guideline Work Group. KDOQI clinical practice guideline for nutrition in CKD: 2020 update. Am. J. Kidney Dis. 2020, 76, S1-S107. [CrossRef]

43. Black, A.E. Critical evaluation of energy intake using the goldberg cut-off for energy intake:basal metabolic rate. A practical guide to its calculation, use and limitations. Int. J. Obes. 2000, 24, 1119-1130. [CrossRef] [PubMed]

44. Harris, J.A.; Benedict, F.G. A Biometric Study of Human Basal Metabolism. Proc. Natl. Acad. Sci. USA 1918, 4, 370-373. [CrossRef] [PubMed]

45. Shah, A.; Bross, R.; Shapiro, B.B.; Morrison, G.; Kopple, J.D. Dietary energy requirements in relatively healthy maintenance hemodialysis patients estimated from long-term metabolic studies. Am. J. Clin. Nutr. 2016, 103, 757-765. [CrossRef] [PubMed]

46. Sterne, J.A.C.; White, I.R.; Carlin, J.B.; Spratt, M.; Royston, P.; Kenward, M.G.; Wood, A.M.; Carpenter, J.R. Multiple imputation for missing data in epidemiological and clinical research: Potential and pitfalls. BMJ 2009, 338, b2393. [CrossRef] [PubMed]

47. Chen, J.; Waqas, K.; Tan, R.C.; Voortman, T.; Ikram, M.A.; Nijsten, T.E.C.; de Groot, L.C.P.G.M.; Uitterlinden, A.G.; Zillikens, M.C. The association between dietary and skin advanced glycation end products: The Rotterdam Study. Am. J. Clin. Nutr. 2020, 112, 129-137. [CrossRef]

48. Hosmer, D.W.; Lemeshow, S.; Sturdivant, R.X. Applied Logistic Regression, 3rd ed.; John Wiley \& Sons, Inc.: Hoboken, NJ, USA, 2013; p. 177.

49. NRR I National Renal Registry: 24th Report of the Malaysian Dialysis \& Transplant Registry 2016. Available online: https: //msn.org.my/nrr/mdtr2016.jsp (accessed on 19 July 2021).

50. Milanovic, Z.; Pantelić, S.; Trajković, N.; Sporis, G.; Kostić, R.; James, N. Age-related decrease in physical activity and functional fitness among elderly men and women. Clin. Interv. Aging 2013, 8, 549. [CrossRef]

51. Zs-Nagy, I. Aging of Cell Membranes: Facts and Theories. Aging 2014, 39, 62-85. [CrossRef]

52. Kuchnia, A.J.; Teigen, L.M.; Cole, A.J.; Mulasi, U.; Gonzalez, M.C.; Heymsfield, S.B.; Vock, D.M.; Earthman, C.P. Phase Angle and Impedance Ratio: Reference Cut-Points From The United States National Health And Nutrition Examination Survey 1999-2004 From Bioimpedance Spectroscopy Data. JPEN J. Parenter. Enter. Nutr. 2016, 41, 1310-1315. [CrossRef] [PubMed]

53. Gracia-Iguacel, C.; González-Parra, E.; Barril-Cuadrado, G.; Sánchez, R.; Egido, J.; Ortiz-Arduán, A.; Carrero, J.J. Defining protein-energy wasting syndrome in chronic kidney disease: Prevalence and clinical implications. Nefrologia 2014, 34, 507-519. [CrossRef] [PubMed] 
54. Vegine, P.M.; Fernandes, A.C.; Torres, M.R.; Silva, M.I.; Avesani, C.M. Assessment of methods to identify protein-energy wasting in patients on hemodialysis. J. Bras. Nefrol. 2011, 33, 55-61. [CrossRef] [PubMed]

55. Berglund, L. Regression Dilution Bias: Tools for Correction Methods and Sample Size Calculation. Upsala J. Med. Sci. 2012, 117, 279-283. [CrossRef]

56. Bennett, D.A.; Landry, D.; Little, J.; Minelli, C. Systematic review of statistical approaches to quantify, or correct for, measurement error in a continuous exposure in nutritional epidemiology. BMC Med. Res. Methodol. 2017, 17, 146. [CrossRef]

57. Wulan, S.N.; Westerterp, K.R.; Plasqui, G. Ethnic Differences in body composition and the associated metabolic profile: A comparative study between Asians and Caucasians. Maturitas 2010, 65, 315-319. [CrossRef]

58. Hui, D.; Dev, R.; Pimental, L.; Park, M.; Cerana, M.A.; Liu, D.; Bruera, E. Association between Multi-Frequency Phase Angle And Survival In Patients With Advanced Cancer. J. Pain Symptom Manag. 2017, 53, 571-577. [CrossRef]

59. Raimann, J.G.; Abbas, S.R.; Liu, L.; Zhu, F.; Larive, B.; Kotanko, P.; Levin, N.W.; Kaysen, G.A. Agreement of Single-and MultiFrequency Bioimpedance Measurements in Hemodialysis Patients: An Ancillary Study of the Frequent Hemodialysis Network Daily Trial. Nephron Clin. Pract. 2014, 128, 115-126. [CrossRef]

60. Karastergiou, K.; Smith, S.R.; Greenberg, A.S.; Fried, S.K. Sex differences in human adipose tissues-The biology of pear shape. Biol. Sex Differ. 2012, 3, 13. [CrossRef]

61. Habibzadeh, F.; Habibzadeh, P.; Yadollahie, M. On determining the most appropriate test cut-off value: The case of tests with continuous results. Biochem. Med. 2016, 26, 297-307. [CrossRef] [PubMed] 